Review

\title{
Meditation and Immune Function: The Impact of Stress Management on the Immune System
}

Nicole Thibodeaux ${ }^{\dagger}$, Matt J. Rossano ${ }^{\dagger}{ }^{*}$

Department of Psychology, Southeastern Louisiana University, Hammond, LA 70402, USA; E-Mails: nicole.thibodeaux@selu.edu; mrossano@selu.edu

† These authors contributed equally to this work.

* Correspondence: Matt J. Rossano; E-Mail: mrossano@selu.edu

Academic Editor: Soo Liang Ooi

Special Issue: Health Benefits of Meditation

OBM Integrative and Complementary Medicine 2018, volume 3 , issue 4

doi:10.21926/obm.icm.1804032
Received: July 16, 2018

Accepted: November 22, 2018

Published: December 3, 2018

\begin{abstract}
:
As alternative forms of medicine have become increasingly popular, research on the health benefits of meditation has grown. Specifically, Mindfulness Meditation, Transcendental Meditation, and Qigong have been shown to be effective in treating psychological disorders, enhancing immune function, and in delaying disease progression in patients diagnosed with HIV, the varicella-zoster virus, and dermatomyositis. This paper briefly reviews the historical background of the many forms of meditation and examines in detail the effects meditation has on several markers of immune function including Natural Killer cell activity, Blymphocytes, telomerase activity, and CD8+ T-cells.
\end{abstract}

\section{Keywords}

Meditation; immune function; inflamation; mindfulness; transcendental meditation; qigong; stress management

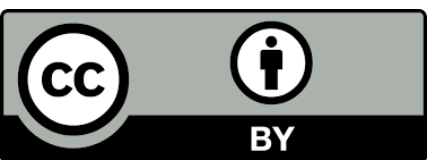

(C) 2018 by the author. This is an open access article distributed under the conditions of the Creative Commons by Attribution License, which permits unrestricted use, distribution, and reproduction in any medium or format, provided the original work is correctly cited. 


\section{Introduction}

\subsection{A Brief Introduction to Meditation}

Despite rapid advances in health care recently, more traditional forms of treatment have gained popularity, as many people, dissatisfied with modern medicine, have been attracted to alternative therapies. One explanation for this shift may be the increase in the median age of the population, as well as the heightened attention on chronic illness and deaths related to individuals' lifestyles [1]. Another explanation may lie in the postmodern thesis [2]. In brief, this thesis suggests a negative correlation between social change and individuals' faith in science and technology. As the pace of societal change increases, individuals are less certain that advances in science and technology will solve society's problems. This includes scepticism about medicine's ability to address individual health problems. This may help to explain why one of humanity's oldest forms of spiritual and therapeutic practice-mediation-has become increasingly popular, especially in the West. This popularity has spurred a substantial amount of research interest as well.

Meditation first emerged in Eastern cultures many centuries ago, as an integral part of both Hindu and Buddhist religious practice. Though the exact time of origin is unknown, the earliest written references to meditation date as far back as the ancient Indian Vedas - a collection of Hindu scriptures written between 1500 and 1000 BCE. By 500 BCE, new forms of meditation began to develop in Buddhist India and Taoist China. Buddhism, in particular, propelled the spread of meditation throughout Asia, and the development of the Silk Road expedited its transmission westward beginning around the First Century CE [3].

However, interest in Eastern forms of meditation did not truly take root in America until the post-War period. In the 1960's, the Hippie subculture emerged, initially as a resistance movement to the Vietnam War. In time, this movement grew frustrated with American materialism, social conservatism and Middle-Class cultural norms in general. As part of this 'rebellion,' Hippies embraced the use of psychoactive drugs and Eastern spiritual practices as means of achieving 'higher' levels of consciousness [4]. Simultaneously, the United States also saw the arrival of Eastern Spiritual teachers due to an expansion of Soviet influence in India, the Cultural Revolution in China, the Communist Chinese takeover of Tibet and Mongolia, and an increase in the political influence of Chinese Communism in Korea and Southeast Asia [5]. Thus, both internal cultural changes and external social/political events led to an opening to Eastern meditative practices in the West.

With its introduction to the West came investigations into the potential health benefits of meditation. Most notable among these early investigations was the work of Jon Kabat-Zinn (whose studies will be discussed in more detail later). Kabat-Zinn's approach sought to isolate the healthrelevant, materialist or 'secular' aspects of meditation. While this was important scientifically, an unintended by-product of it (among the general public, at least) was a glossing over of important cultural or religious distinctions among different meditative forms. Such 'Westernizing' or 'Americanizing' of meditation created definitional challenges as various Eastern practices were lumped into one, often over-simplified, category [6]. While acknowledging that the distinctions 
outlined in this review are still rather general, it is important to recognize that at least three distinct forms of mediation have been found to have important health implications: Mindfulness Meditation, Transcendental Meditation, and Qigong.

\subsection{Mindfulness Meditation}

One of the earliest standardized forms of Mindfulness Meditation began in 1979 with Jon Kabat-Zinn's creation of the Mindfulness-Based Stress Reduction (MBSR) program [7]. In brief, mindfulness is one of the stages listed in Buddha's eightfold path-designed as a pathway to enlightenment and, in turn, a prescription to end suffering. The eight divisions of the path, focusing on ethical conduct, mental discipline, and wisdom are as follows: right understanding (samma ditthi), right thought (samma sankappa), right speech (samma vaca), right action (samma kammanta), right livelihood (samma ajiva), right effort (samma vayama), right concentration (samma samadhi), and mindfulness (samma sati). It should be noted these divisions are not dependent on one another and not intended to be followed in a linear fashion [8]. Mindfulness is achieved when the individual develops an uninvolved awareness of his or her body, sensations, feelings, and states of mind [9]. Mindfulness does not equate to thought suppression. Instead, an individual who has reached a state of mindfulness has a non-elaborative awareness of thoughts, feelings, and sensations. Thus, passing thoughts or feelings are acknowledged but in a detached, non-judgmental way [10]. In doing so, the individual is able to free their attention and fully experience all aspects of life, coping with negativity in a healthy way. Kabat-Zinn based his 8-week program on this definition, suggesting it be used to accompany modern medicine in the management of stress-related disorders and chronic pain.

While the underlying mechanisms that make Mindfulness Meditation effective are not fully understood, researchers believe shifts in self-regulation, values clarification, and cognitivebehavioural flexibility play important roles [11]. Through self-regulation, individuals free themselves from maladaptive behaviours and ruinous thoughts by gaining authority over their responses. Mindfulness equates to being fully present in the moment, requiring skill in sustained attention and switching of attention [10]. Sustained attention consists of maintaining focus on the present, while attention switching requires bringing attention that has strayed back to the present. This allows individuals to understand and disengage from passing thoughts and behaviours, keeping their attention in the 'immediate now'.

Similarly, values clarification allows individuals to rediscover their own values, rather than the values of society. Through the discovery of these values, individuals develop greater skill in mastering their thoughts and actions in a manner congruent with their beliefs. Cognitive and behavioural flexibility evolve in conjunction with self-regulation and values clarification. By disciplinging one's thoughts with self-regulation and changing one's behaviours through values clarification, individuals become more flexible and adaptive in their responses. Rather than initiating autonomic or reactive responses, individuals become aware of the present situation, evaluate its importance, and excercise greater skill in choosing beneficial reactions.

A by-product of mindfulness practice is often an increase in the breadth of one's emotional experience. By enhancing one's awareness of sensory, cognitive, and behavioural states, individuals allow themselves 'space' to consciously process and understand their emotional reactions rather than having those emotions overwhelm them. Gaining insight into one's 
emotional reactions leads to a recognition that those reactions are temporary and tolerable, subsequently reducing fear and feelings of defeat.

In sum, while Mindfulness Meditation as practiced today is often heavily 'Americanized,' in his original implementation of the MBSR, Kabat-Zinn intertwined Buddhist teachings with Western culture to construct an effective intervention program. The program has gained widespread acceptance. As of 2015 , almost $80 \%$ of medical schools in the United States implemented some form of mindfulness training for their students [12]. Additionally, research supports the effectiveness of such interventions, as they have been shown to have positive effects on stressrelated ailments, psychiatric disorders, and disease symptomatology [13-15].

\subsection{Transcendental Meditation}

Similarly, Transcendental Meditation (TM) is another type of stress reduction technique, focused on the integration of the mind and body. During the process of transcending, individuals utilize a mantra - a sound without meaning repeated within the mind-to quiet their thoughts until their mind reaches the silent state of transcendental consciousness. The mantra is used as a focal point for the individual, allowing all other thoughts to be disregarded. If the individual is successful, the body will enter transcendental consciousness wherein it is calmed and quieted. The individual's heart rate and breathing begin to slow, counteracting the increases typically seen during a stress response [16]. This quieted physiological state can have positive impacts on stress related ailments and diseases. Most notably, research has shown that TM may improve outcomes for those diagnosed with hypertension, cardiovascular disease, and high cholesterol [16-19].

\subsection{Qigong}

Qigong, which includes slow, coordinated movements, controlled breathing, and meditation is yet another method implemented to improve the relationship between the breath, the body, and the mind [20]. Controlled movements are meant to strengthen and stretch the body, while controlled breathing and meditation are used to quiet the mind, inducing a state of relaxation. More recently, medical Qigong has been developed as a variation of the traditional Chinese technique, with the sole intent to treat and cure disease. In this variation, practitioners employ qi in their treatment of illnesses [21].

While qi has not been scientifically verified, it is believed to be a vital life force that flows through meridians, or channels, in the body. The movements and meditation associated with Qigong are thought to increase the flow of qi, promoting balanced energy and health within the individual, while strengthening performance of both the mind and body [22]. As with Mindfulness and Transcendental Meditation, Qigong has several documented benefits including the treatment of psychosomatic disorders and hypertension while also reducing sympathetic nervous system activity (flight or fight responding) and enhancing parasympathetic activity through increasing individuals' relaxation response [23, 24].

Though the mechanisms may only be partially understood, it seems clear that meditative practices such as MBSR, TM, and Qigong have positive self-reported health effects. An important step in further elucidating these mechanisms is to investigate the physiological implications of meditative practices. Recently, a considerable amount of research attention has focused on 
meditation and immune system function. It appears that one of the pathways by which meditative practices improve health is by enhancing immune function.

\section{Results}

\subsection{Meditation and Immune Function}

A wide array of research has been conducted examining the relationship between meditation and immune function. From the outset, it should be understood that immune function can be complex and mere increases in immune cell numbers or activity do not necessarily mean that health or healing are significantly improved. However, bolstering immune function is typically advantegous to health, and activities (such as mediation or exercise) that appear to do that are often encouraged by health practioners.

Mind and body share a bidirectional relationship. Psychoneuroimmunology is a term used to describe the interaction between psychological factors, the central nervous system, and the neuroendocrine system [25]. In reference to the relationship between the central nervous system and the neuroendocrine system, animal research has shown that brain lesions in the left and right hemispheres produce different effects on immune function [26]. In addition, it has also been shown that these two systems utilize a biochemical language consisting of shared hormones, neurotransmitters, and cytokines, to effectively communicate [27]. Furthermore, psychological factors, such as stress and emotions, influence the brain-immune relationship. Specifically, acute stressors enhance immunity while chronic stressors suppress immune function [28].

\subsection{Regulation of the Immune System}

The up and down regulation of immune function may be seen as an adaptive mechanism regulated by stress hormones. The chronic release of stress hormones can create an allostatic load (a form of physiological 'wear and tear') producing immune system dysfunction and suppression $[29,30]$. For instance, chronic stress impairs immune system response [31] as well as triggering inflammation [32, 33]. Specifically, elevated corticotropin releasing hormone (CRH) provokes the production of pro-inflammatory cytokines [34]. Negative emotions can also suppress immune function through their tendency to promote telomere shortening and increased NFkB activity [3538]. However, as mentioned earlier, mind-body effects are bi-directional. The stress-reduction and positive affect associated with meditative practices can undo many of the physiological reactions leading to inflammation and reduced immune function brought on by negative emotions and stress.

\subsection{Inflammation and Meditation}

As previously mentioned, chronic stress suppresses immune function. One pathway through which this occurs is the inflammatory response. In brief, immune cells produce inflammatory cytokines-proteins that regulate the immune response to injury and infection - which have either pro-inflammatory or anti-inflammatory effects. Pro-inflammatory cytokines promote inflammation as an early defence against injury or infection. These cytokines consist of interleukin 1 (IL-1), interleukin 6 (IL-6), interleukin 8 (IL-8) and tumor necrosis factor (TNF)- $\alpha$ [39]. In addition, C- 
reactive protein (CRP) is an acute inflammatory protein, which acts as a marker of inflammation due to an increase in CRP levels when inflammation occurs [40]. Specifically, IL-6 stimulates the production of CRP [41]. Nuclear factor kappa B (NFKB) also plays a role in inflammation. NFkB is responsible for mediating the synthesis of pro-inflammatory cytokines [42]. Like CRP, NFKB activity is increased with inflammation. The chronic elevation of NFKB activity is associated with inflammatory diseases such as inflammatory bowel disease, arthritis, and atherosclerosis.

Chronic elevation of pro-inflammatory cytokines hinders the body's ability to heal wounds and fight infections as well as increasing individuals' risk for ailments such as heart disease, type 2 diabetes, and osteoporosis [43]. Furthermore, elevated IL-6 and CRP are associated with an increased risk of cardiovascular disease and mortality [40]. Psychological stress is known to elevate both IL-6 and CRP [37, 44], thus producing increased levels of circulating pro-inflammatory cytokines [45-47], dampening the immune response to infection and injury [39]. Mindfulness interventions, however, are known to reduce stress, and have been shown to decrease proinflammatory cytokines, including: IL-6 [45, 48, 49], TNF- $\alpha[50,51]$, CRP $[45,52-54]$, and NFkB [48, $52,55-58]$. In this way, mindfulness practices protect the immune system from the stress- and emotion-triggered physiological processes that degrade it. Meditation's benefits, however, go beyond just being protective. Evidence indicates that it can enhance immune function as well.

\subsection{Natural Killer Cells, B-lymphocytes, and Meditation}

Meditation enhances immune function through different mechanisms. Several studies have shown that different forms of meditation result in an increase in natural killer (NK) cells and Blymphocytes. NK cells are white blood cells that target and kill stressed or abnormal cells, playing a role in tumour prevention and serving as an early defence against viral infections. A decrease in these cells may result in the development or progression of different forms of cancer, acute and chronic viral infections, and various autoimmune diseases [59]. Similarly, B-lymphocytes are responsible for antibody production, which attack invading viruses, toxins, and bacteria. In addition, B-lymphocytes also regulate homeostasis through wound healing, rejection of transplants, and the activation of T-cells [60].

Regarding the association between these immune components and meditation, research has shown an increase in NK activity in healthy individuals who practiced a form of yoga entailing TM mediation techniques [61]. Eight advanced yoga instructors were directed to engage in different forms of meditation. Specifically, the instructors participated in a form of rhythmic breathing, called pranayama, which was then followed by a period of meditation using a mantra, similar to that used in TM. NK activity was then measured through blood samples collected at the beginning and end of each activity. It was found that NK cell activity was increased during pranayama, correlated with a significant increase in alpha wave activity in the brain signalling a state of reduced stress. Therefore, researchers concluded that the stress reduction associated with rhythmic breathing is capable of increasing NK activity, strenghtening immune function.

In addition, the regular practice of TM has been shown to affect the number of circulating Blymphocytes and NK cells [62]. Researchers compared anxiety levels and immune cell activity between a group of advanced TM practitioners and a control group, consisting of participants unfamiliar with yoga or meditation. Both groups consisted of healthy individuals, following a Mediterranean diet. While there was no significant difference in anxiety levels, blood samples 
revealed thatTM practitioners had more B-lymphocytes and NK cells than the control group. This raises the possibility that $\mathrm{TM}$ could bolster immune function leading to an increased ability to combate infection and disease. However, given the scarcity of studies directly addressing this issue, empirical validation of this is yet to be firmly established.

In contrast, Qigong has been shown to reduce the proportion of NK cells, while increasing the number of B-lymphocytes [63]. In this study, participants consisted of forty-three healthy, nonathlete university students, who had no previous experience with yoga or meditation. Twenty-five participants were instructed to attend a qigong class for thirty minutes three times per week, lasting for one month. Researchers encouraged these participants to practice additional qigong outside of class, but did not require it. Eighteen individuals composed the control group who received no Qigong training or practice. Blood samples from all participants were collected when the study began, after the last Qigong class concluded, and an additional sample was collected one month after the classes ended. Immediately after the last Qigong session, the experimental group had a lower percentage of NK cells. However, this group also had a higher number and percentage of B-lymphocytes. The reduction in NK cells could be due to the movement component present in Qigong. NK cells are known to be more sensitive to exercise, depending on several factors such as intensity, duration, and the time between activity and blood collection [64]. By contrast, Blymphocytes are hypothesized to be more sensitive to relaxation [65]. Thus, the reduction in NK cells may not be entirely unexpected given the nature of Qigong.

It is important to note that similar research, while not finding significant evidence for a change in NK cells, did find an increase in the cytotoxic activity of the NK cells [66]. Blood samples collected immediately after a Qigong intervention showed an increase in the cytotoxicity of NK cells but no change in the number of NK cells present, with the increase in cytotoxicity lasting for two hours post exercise. An increase in cytotoxicity allows the NK cells to more effectively diminish threatening cells. In sum, this evidence suggests that TM and Qigong significantly influence NK cells and B-lymphocytes, positively altering immune function.

\subsection{Telomeres, Telomerase Activity, and Meditation}

Meditation has also been found to positively influence telomerase activity in immune cells. Human DNA consists of caps, called telomeres, located on the end of each chromosome. These 'caps' can offer protection from cellular deterioration and senescence, which occur when a telomere becomes too short, preventing cellular division [67-69]. Oxidative damage is known to shorten telomeres, a condition significantly associated with cell aging and higher rates of mortality in humans [70, 71]. Other factors that affect telomere length include age, poor diet, sedentary lifestyles, lack of sleep, smoking, overconsumption of alcohol, and psychological stress.

Telomerase is an enzyme responsible for regulating telomere length. Increasing telomerase levels, which in turn increases its activity, provides a buffer against the degeneration of telomeres associated with oxidative damage [67]. While this enzyme is abundant in stem cells [72], it is generally found in very low levels or not at all in somatic cells [73, 74]. Research has shown that physical exercise and a healthy body mass index (BMI) may promote telomerase [75, 76]. Additionally, meditation may be associated with longer telomeres [35, 77-81] and increased telomerase activity [80-84]. In one study, for example [84] nearly one hundred healthy individuals participated in a yoga and meditation intervention five times per week for twelve weeks. While 
blood samples did not show a substantial change in telomere length, telomerase activity was significantly increased compared to baseline levels.

A similar effect was found in individuals diagnosed with breast cancer. Lengacher et al. [83] implemented a MBSR program with breast cancer survivors. As with healthy individuals, the breast cancer survivors showed no difference in telomere length but telomerase activity was significantly increased when compared to the control group. While more research is needed to fully understand the mechanisms responsible for this change, increased telomerase activity in response to yoga and meditation may be due to the relationship between telomerase and cortisol levels [81]. Stress responses trigger a release of $\mathrm{CRH}$ further increasing oxidative damage [34]. As previously stated, meditation may decrease stress, anxiety, and depression, all of which increase cortisol levels and lower telomerase activity $[70,85]$. While a relationship among meditation, telomeres, and telomerase activity exists, further research will likely be necessary to unravel the exact mechanism(s) at work.

\subsection{CD8+ T-Cells and Meditation}

Another biological indicator of the positive effects of meditation on immune system function is the activity of CD8+ T-cells. These are white blood cells responsible for removing damaged and infected cells, preventing the spread of viruses and cancers. These cells are known to increase as a result of strenuous exercise [86]. During periods of prolonged physical stress, such as the stress of vigorous exercise, the presence of CD8+ T- cells in the blood is known to increase. However, in the recovery period after prolonged stress, CD8+ T-cells drop below baseline leading to immune system suppression and increased vulnerability to infection. Some evidence suggests [87] that by moderating the initial CD8+ T-cell increase under stress, meditation can reduce the recoveryperiod immune system suppression and therefore the individual's vulnerability to infection.

Similarly, meditation has also been documented to increase the antibody response to injections of the influenza vaccine, in correlation with increase activation of anterior, left-hemisphere areas of the brain [88]. Anterior left-hemisphere brain activity is known to be associated with positive emotions [89] as well as increases in NK cell activity [90]. Davidson et al. recruited twenty-five individuals to practice meditation for an eight-week period, followed by an injection of the influenza vaccination. As expected, participants experienced greater left-sided brain activation both immediately after and four months after the intervention as compared to controls. In addition to the brain activation, meditators also showed a significant increase in antibodies to the influenza vaccination when compared to the control group. This suggests that meditation has the capability to bolster acute immune response to infection.

\subsection{Disease Progression and Meditation}

Several studies report a significant effect of meditation in the treatment of various diseases. In HIV positive individuals, meditation has been shown to increase T-cell counts [91], as well as NK cell numbers and activity [92]. While the specific mechanisms responsible for these increases are unknown, researchers suggest that the reduction in depression and stress-reducing effects of meditation may play a key role. Specifically, MBSR interventions have been shown to decrease depression and negative affect in healthy individuals [93], as well as HIV positive individuals [94]. This relationship is further supported by evidence demonstrating the adverse effects of stress and 
depression on HIV acceleration, including immune suppression and deceleration of CD4+ Tlymphocyte levels [95-97]. It should be noted that HIV progression is measured by an individual's CD4+ T-cell counts, with lowered levels signifying progression of the disease [98]. These lymphocytes are responsible for the activation of other immune cells, such as B-lymphocytes and CD8+ T-cells, which destroy damaged and infected cells. A depletion of CD4+ T-lymphocytes, as seen in HIV, leaves the body susceptible to a wide array of viruses, as well as an accelerated progression of HIV [99]. Research has demonstrated that meditation may delay HIV progression by safeguarding against the destruction of CD4+ T-lymphocytes by the virus and in some cases, increasing the amount present [100-102]. Additionally, Robinson et al. [92] found evidence of increased NK cell numbers and cytotoxic activity of cells of HIV positive individuals following a MBSR intervention. Therefore, through meditation's stress-reducing effects, it has the potential to significantly slow the progression of HIV by enhancing immune function.

Single-subject designs have also been used to study the effects of meditation on disease progression and immune function. While these studies have obvious limitations, they can be advantegous in that symptomological severity and change can be mapped in detail. One such study revealed the ability of an experienced meditator to modulate her immune system after being injected with the varicella-zoster antigen, better known as the virus responsible for chickenpox and shingles. Through meditation and the direction of "healing energies" to the site of injection, the individual successfully delayed skin hypersensitivity and inhibited lymphocyte response to the varicella-zoster antigen [103].

Another single-subject study used two forms of mind-body intervention to help a patient recovering from dermatomyositis, an inflammatory disease leading to muscle weakness and itchy, painful rashes. Specifically, transcendental meditation and visual imagery were shown to lead to remission by improving arm strength and reducing rash and pain on the hands [104]. As with HIV, psychological stress has negative implications for dermatomyositis through immune suppression. While the specific cause of this disease is unknown, its etiology is similar to that of autoimmune diseases. Consequently, stress reduction acquired through meditation has the ability to effectively improve immune function, reducing the symptomology associated with the disease.

\section{Conclusions}

Practicing meditation has several benefits, including reducing the severity of psychological disorders and stress-related ailments, increasing immune function, and delaying the progression of various diseases. Researchers have found that Mindfulness Meditation, Transcendental Meditation, and Qigong interventions have positive effects on individuals' NK cell activity and proportions, B-lymphocyte numbers, and telomerase activity, while also keeping CD8+ T-cell numbers stable during times of high stress. In addition, meditation has also been shown to increase antibody response in individuals injected with the influenza vaccine. Similarly, HIV positive individuals practicing meditation showed increased T-cell and NK cell counts and NK cell activity, slowing the progression of the virus. Similarly, positive effects have also been observed in an individual injected with the varicella zoster antigen as well as a patient diagnosed with dermatomyositis. However, an important limitation of these findings needs to be acknowledged: the extent to which these positive effects in immune function are robust enough to prevent 
disease, significantly speed healing, or increase longevity is still largely unknown. Definitively answering these questions requires further empirical work.

While still very much in its infancy, scientific studies of meditation are providing compelling evidence of the relevance of the mind-body connection in human health. In times past, ritual and spiritual practices were humanity's primary forms of health care. With the advent of modern medicine, those practices have often been dismissed as part of our irrational, superstitious past. We note with a bit of irony, that it is science itself which offers validation for the effectiveness of these practices (at least in under some circumstances). Furthermore, science offers a mechanism by which meditative practices reap their physical rewards. By altering attitudes, perceptions, and cognitions, meditation reduces stress, which in turn strengthens immune function. A more robust immune system is advantageous to health, healing, and longevity.

\section{Acknowledgments}

The authors thank the editors of this special addition of OBM Integrative and Complementary Medicine for the opportunity to write this review. Acknowledge the people or organization(s) that have technically supported this work, excluding fund provider.

\section{Author Contributions}

The authors contributed equally to the writing of the paper.

\section{Competing Interests}

The authors have declared that no competing interests exist.

\section{References}

1. Coulter ID, Willis EM. The rise and rise of complementary and alternative medicine: a sociological perspective. Med J Aust. 2004; 180: 587-589.

2. Siahpush M. Postmodern values, dissatisfaction with conventional medicine and popularity of alternative therapies. J Sociol. 1998; 34: 58-70.

3. Elverskog J. Buddhism and islam on the Silk Road. Philidephia: University of Pennsylvania Press; 2011.

4. Coleman JW. The new buddhism: The western transformation of an ancient tradition. New York: Oxford University Press; 2001.

5. Murphy M, Donovan S, Taylor E. The physical and psychological effects of meditation: A review of contemporary research with a comprehensive bibliography. Sausalito: Institute of Noetic Sciences; 1997.

6. Bond K, Ospina MB, Hooton N, Bialy L, Dryden DM, Buscemi N, et al. Defining a complex intervention: The development of demarcation criteria for "Meditation". Psychol Religion Spirituality. 2009; 1: 129-137.

7. Kabat-Zinn J. An outpatient program in behavioural medicine for chronic pain patients based on the practice of mindfulness meditation: Theoretical considerations and preliminary results. Gen Hosp Psychiat. 1982; 4: 33-47.

8. Bodhi B. The noble eightfold path: The way to the end of suffering. Kandy: Buddhist 
Publication Society; 1984.

9. Kang C, Whittingham K. Mindfulness: A dialogue between Buddhism and clinical psychology. Mindfulness. 2010; 1: 161-173.

10. Bishop SR, Lau M, Shapiro S, Carlson L, Anderson ND, Carmody J, et al. Mindfulness: A proposed operational definition. Clin Psychol Sci Pract. 2004; 11: 230-241.

11. Shapiro SL, Carlson LE, Astin JA, Freedman B. Mechanisms of mindfulness. J clin psychol. 2006; 62: 373-386.

12. Buchholz L. Exploring the promise of mindfulness as medicine. J Am Med Assoc. 2015; 314: 1327-1329.

13. Goyal M, Singh S, Sibinga EMS, Gould NF, Rowland-Seymour A, Sharma R, et al. Meditation programs for psychological stress and well-being: $A$ systematic review and metaanalysis. JAMA Intern Med. 2014; 174: 357-368.

14. Grossman $P$, Niemann L, Schmidt S, Walach H. Mindfulness-based stress reduction and health benefits. A meta-analysis. J Psychosom Res. 2004; 57: 35-43.

15. Hofmann SG, Sawyer AT, Witt AA, Oh D. The effect of mindfulness based therapy on anxiety and depression: A meta-analytic review. J Consulting Clin Psychol. 2010; 78: 169-183.

16. Forem J. Transcendental meditation. London: Hay House; 2012.

17. Castillo-Richmond A, Schneider RH, Alexander CN, Cook R, Myers H, Nidich S, et al. Effects of stress reduction on carotid atherosclerosis in hypertensive African Americans. Stroke. 2000; 31: 568-573.

18. Rainforth MV, Schneider RH, Nidich SI, Gaylord-King C, Salerno JW, Anderson JW. Stress reduction programs in patients with elevated blood pressure: A systematic review and metaanalysis. Curr Hypertens Rep. 2007; 9: 520-528.

19. Walton KG, Schneider RH, Nidich S. Review of controlled research on the transcendental meditation program and cardiovascular disease: Risk factors, morbidity, and mortality. Cardiol Rev. 2004; 12: 262-266.

20. Dorcas A, Yung P. Qigong: harmonising the breath, the body and the mind. Complement Ther Nurs Midwifery. 2003; 9: 198-202.

21. Lee MS, Lim HJ, Lee MS. Impact of Qigong exercise on self-efficacy and other cognitive perceptual variables in patients with essential hypertension. J Altern Complement Med. 2004; 10: 675-680.

22. Jahnke R, Larkey L, Rogers C, Etnier J, Lin F. A comprehensive review of health benefits of Qigong and Tai Chi. Am J Health Promot. 2010; 24: e1-e25.

23. Lee MS, Ryu H, Chung HT. Stress management by psychosomatic training: Effects of ChunDoSunBup Qi-training on symptoms of stress: A cross-sectional study. Stress Med. 2000; 16: 161-166.

24. Lee MS, Huh HJ, Kim BG, Ryu H, Lee HS, Kim JM, et al. Effects of Qi-training on heart rate variability. Am J Chin Med. 2002; 30: 463-470.

25. Ader R, Cohen N. Behaviorally conditioned immunosuppression. Psychosom Med. 1975; 37: 333-340.

26. Biziere K, Guillaumin JM, Degenne D, Bardos P, Renoux M. Neural modulation of immunity. New York: Raven Press; 1985. (p. 81-94)

27. Carr DJJ, Blalock JE. Psychoneuroimmunology. 2nd ed. New York: Academic Press; 1991. (p. 573-588). 
28. Dhabhar FS, McEwen BS. Acute stress enhances while chronic stress suppresses cell-mediated immunity in vivo: A potential role for leukocyte trafficking. Brain Behav Immun. 1997; 11: 286-306.

29. McEwen BS. Stress, adaptation, and disease. Allostasis and allostatic load. Ann N Y Acad Sci. 1998; 840: 33-44.

30. Zachariae R. Psychoneuroimmunology: A bio-psycho-social approach to health and disease. Scand J Psychol. 2009; 50: 645-651.

31. Segerstrom SC, Miller GE. Psychological stress and the human immune system: a metaanalytic study of 30 years of inquiry. Psychol Bull. 2004; 130: 601-630.

32. Pace TW, Negi LT, Adame DD, Cole SP, Sivilli TI, Brown TD, et al. Effect of compassion meditation on neuroendocrine, innate immune and behavioural responses to psychosocial stress. Psychoneuroendocrino. 2009; 34: 87-98.

33. Welk U, Herforth A, Kolb-Bachofen V, Deinzer R. Acute stress induces proinflammatory signalling at chronic inflammation sites. Psychosom Med. 2008; 70: 906-912.

34. Wang W, Ji P, Dow KE. Corticotropin-releasing hormone induces proliferation and TNF-alpha release in cultured rat microglia via MAP kinase signalling pathways. J Neurochem. 2003; 84: 189-195.

35. Epel E, Daubenmier J, Moskowitz JT, Folkman S, Blackburn E. Can meditation slow rate of cellular aging? Cognitive stress, mindfulness, and telomeres. Ann N Y Acad Sci. 2009; 1172: 34-53.

36. O’Donovan A, Tomiyama AJ, Lin J, Puterman E, Adler NE, Kemeny M, et al. Stress appraisals and cellular aging: A key role for anticipatory threat in the relationship between psychological stress and telomere length. Brain Behav Immun. 2012; 26: 573-579.

37. Steptoe A, Hamer M, Chida $Y$. The effects of acute psychological stress on circulating inflammatory factors in humans: A review and meta-analysis. Brain Behav Immun. 2007; 21: 901-912.

38. Zachariae R, Bjerring P, Zachariae C, Arendt-Nielsen L, Nielsen T, Eldrup E, et al. Monocyte chemotactic activity in sera after hypnotically induced emotional states. Scand J Immunol. 1991; 34: 71-79.

39. Glaser R, Kiecolt-Glaser JK, Marucha PT, MacCallum RC, Laskowski BF, Malarkey WB. Stressrelated changes in proinflammatory cytokine production in wounds. Arch Gen Psychiat. 1999; 56: 450-456.

40. Sproston NR, Ashworth JJ. Role of C-reaction protein at sites of inflammation and infection. Front Immunol. 2018; 9: 754.

41. Tanaka $T$, Kishimoto $T$. The biology and medical implications of interleukin-6. Cancer Immunol Res. 2014; 2: 288-294.

42. Lawrence T. The nuclear factor NF-KB pathway in inflammation. CSH Perspect Biol. 2009; 1: a001651.

43. Chrousos GP. Stress, chronic inflammation, and emotional and physical well-being: Concurrent effects and chronic sequelae. J Allergy Clin Immunol. 2000; 106: S275-S291.

44. Kiecolt-Glaser JK, Preacher KJ, MacCallum RC, Atkinson C, Malarkey WB, Glaser R. Chronic stress and age-related increases in the proinflammatory cytokine IL-6. P Natl Acad Sci USA. 2003; 100: 9090-9095. 
45. Creswell JD, Taren AA, Lindsay EK, Greco CM, Gianaros PJ, Fairgrieve A, et al. Alterations in resting-state functional connectivity link mindfulness meditation with reduced interleukin-6: a randomized controlled trial. Biol Psychiat. 2016; 80: 53-61.

46. DeRijk R, Michelson D, Karp B, Petrides J, Galliven E, Duester P, et al. Exercise and circadian rhythm-induced variations in plasma cortisol differentially regulate interleukin-1 beta (IL-1 beta), IL-6, and tumor necrosis factor- alpha (TNF-alpha) production in humans: high sensitivity of TNF-alpha and resistance of IL-6. J Clin Endocr Metab. 1997; 82: 2182-2192.

47. Zhou D, Kusnecov AW, Shurin MR, DePaoli M, Rabin BS. Exposure to physical and psychological stressors elevates plasma interleukin 6: Relationship to the activation of hypothalamic-pituitary-adrenal axis. Endocrinology. 1993; 133: 2523-2530.

48. Bower JE, Creswell AD, Stanton AL, Crespi CM, Winston D, Arevalo J, et al. Mindfulness meditation for younger breast cancer survivors: a randomized controlled trial. Cancer. 2015; 121: 1231-1240.

49. Lengacher CA, Kip KE, Barta M, Post-White J, Jacobsen PB, Groer M, et al. A pilot study evaluating the effect of mindfulness-based stress reduction on psychological status, physical status, salivary cortisol, and interleukin- 6 among advanced-stage cancer patients and their caregivers. J Holist Nurs. 2012; 30: 170-185.

50. Elsenbruch S, Langhorst J, Popkirowa K, Müller T, Luedtke R, Franken U, et al. Effects of mindbody therapy on quality of life and neuroendocrine and cellular immune functions in patients with ulcerative colitis. Psychother Psychosom. 2005; 74: 277-287.

51. Rosenkranz MA, Davidson RJ, Maccoon DG, Sheridan JF, Kalin NH, Lutz A. A comparison of mindfulness-based stress reduction and an active control in modulation of neurogenic inflammation. Brain Behav Immun. 2013; 27: 174-184.

52. Creswell JD, Irwin MR, Burklund L, Lieberman MD, Arevalo JM, Ma J, et al. Mindfulness-based stress reduction training reduces loneliness and pro-inflammatory gene expression in older adults: a small randomized controlled trial. Brain Behav Immun. 2012; 26: 1095-1101.

53. Jedel S, Hoffman A, Merriman P, Swanson B, Voigt R, Rajan KB, et al. A randomized controlled trial of mindfulness-based stress reduction to prevent flare-up in patients with inactive ulcerative colitis. Digestion. 2014; 89: 142-155.

54. Malarkey WB, Jarjoura D, Klatt M. Workplace based mindfulness practice and inflammation: a randomized trial. Brain Behav Immun. 2013; 27: 145-154.

55. Bhasin MK, Dusek JA, Chang BH, Joseph MG, Denninger JW, et al. Relaxation response induces temporal transcriptome changes in energy metabolism, insulin secretion and inflammatory pathways. PloS One. 2013; 8: e62817.

56. Black DS, O'Reilly GA, Olmstead R, Breen EC, Irwin MR. Mindfulness-based intervention for prodromal sleep disturbances in older adults: Design and methodology of a randomized controlled trial. Contemp Clin Trials. 2014; 39: 22-27.

57. Black DS, O'Reilly G A, Olmstead R, Breen EC, Irwin MR. Mindfulness meditation and improvement in sleep quality and daytime impairment among older adults with sleep disturbances: A randomized clinical trial. JAMA Intern Med. 2015; 175: 494-501.

58. Bower JE, Irwin MR. Mind-body therapies and control of inflammatory biology: A descriptive review. Brain Behav Immun. 2016; 51: 1-11.

59. Whiteside TL, Herberman RB. Role of human natural killer cells in health and disease. Clin Diagn Lab Immunol. 1994; 1: 125-133. 
60. LeBien TW, Tedder TF. B lymphocytes: how they develop and function. Blood. 2008; 112: 1570-1580.

61. Kamei T, Toriumi Y, Kimura H, Kimura K. Correlation between alpha rhythms and natural killer cell activity during yogic respiratory exercise. Stress Health J Int Soc Invest Stress. 2001; 17: 141-145.

62. Infante JR, Peran F, Rayo JI, Serrano J, Dominguez ML, Garcia L, et al. Levels of immune cells in transcendental meditation practitioners. Int J Yoga. 2014; 7: 147-151.

63. Vera FM, Manzaneque JM, Rodríguez FM, Bendayan R, Fernández N, Alonso A. Acute effects on the counts of innate and adaptive immune response cells after 1 month of Taoist Qigong Practice. Int J Behav Med. 2016; 23: 198-203.

64. Klarlund B, Hoffman-Goetz L. Exercise and the immune system: regulation, integration, and adaptation. Physiol Rev. 2000; 80: 1055-1081.

65. Lee MS, Huh HJ, Jeong SM, Jang HS, Ryu H, Park JH, et al. Effects of Qigong on immune cells. Am J Chin Med. 2003; 31: 327-335.

66. Lee MS, Kang CW, Ryu $\mathrm{H}$. Acute effect of qi-training on natural killer cell subsets and cytotoxic activity. Int J Neurosci. 2005; 115: 285-297.

67. Blackburn EH. Telomere states and cell fates. Nature. 2000; 408: 53-56.

68. Chan SRWL, Blackburn EH. Telomeres and telomerase. Philos T R Soc B Biol Sci. 2004; 359 : 109-121.

69. Fossel M. Role of cell senescence in human aging. J Anti-Aging Med. 2000; 3: 91-98.

70. Epel ES, Blackburn EH, Lin J, Dhabhar FS, Adler NE, Morrow JD, et al. Accelerated telomere shortening in response to life stress. PNAS. 2004; 101: 17312-17315.

71. Cawthon R, Smith K, O'Brien E, Sivatchenko A, Kerber R. Association between telomere length in blood and mortality in people aged 60 years or older. Lancet. 2003; 361: 393-395.

72. Blackburn EH, Epel ES, Lin J. Human telomere biology: A contributory and interactive factor in aging, disease risks, and protection. Science. 2015; 350: 1193-1198.

73. Blackburn EH, Greider CW, Szostak JW. Telomeres and telomerase: the path from maize, Tetrahymena and yeast to human cancer and aging. Natl Med. 2006; 12: 1133-1138.

74. Lopez-Otin C, Blasco MA, Partridge L, Serrano M, Kroemer G. The hallmarks of aging. Cell. 2013; 153: 1194-1217.

75. Puterman E, Lin J, Blackburn E, O'Donovan A, Adler N, Epel E. The power of exercise: Buffering the effect of chronic stress on telomere length. PLoS ONE. 2010; 5: e10837.

76. Sun Q, Shi L, Prescott J, Chiuve SE, Hu FB, De Vivo I, et al. Healthy lifestyle and leukocyte telomere length in US women. PloS One. 2012; 7: e38374.

77. Alda $M$, Puebla-Guedea $M$, Rodero B, Demarzo $M$, Montero-Marin J, Roca $M$, et al. Zen meditation, length of telomeres, and the role of experiental avoidance and compassion. Mindfulness. 2016; 7: 651.

78. Hoge EA, Chen MM, Orr E, Metcalf CA, Fischer LE, Pollack MH, et al. Loving-Kindness Meditation practice associated with longer telomeres in women. Brain Behav Immun. 2013; 32: 159-163.

79. Hoge EA, Hölzel BK, Marques L, Metcalf CA, Brach N, Lazar SW, et al. Mindfulness and selfcompassion in generalized anxiety disorder: Examining predictors of disability. Evid Based Complement Alternat Med. 2013; doi: 10.1155/2013/576258.

80. Jacobs TL, Epel ES, Lin J, Blackburn EH, Wolkowitz OM, Bridwell DA, et al. Intensive meditation 
training, immune cell telomerase activity, and psychological mediators. Psychoneuroendocrino. 2011; 36: 664-681.

81. Schutte NS, Malouff JM. A meta-analytic review of the effects of mindfulness meditation on telomerase activity. Psychoneuroendocrino. 2014; 42: 45-48.

82. Lavretsky H, Epel ES, Siddarth P, Nazarian N, Cyr NS, Khalsa DS, et al. A pilot study of yogic meditation for family dementia caregivers with depressive symptoms: effects on mental health, cognition, and telomerase activity. Int J Geriatr Psychiat. 2013; 28: 57-65.

83. Lengacher CA, Reich RR, Kip KE, Barta M, Ramesar S, Paterson CL, et al. Influence of mindfulness-based stress reduction (MBSR) on telomerase activity in women with breast cancer (BC). Biol Res Nurs. 2014; 16: 438-447.

84. Tolahunase M, Sagar R, Dada R. Impact of yoga and meditation on cellular aging in apparently healthy individuals: A prospective, open-label single-arm exploratory study. Oxid Med Cell Longev. 2017; doi: 10.1155/2017/7928981.

85. Epel ES, Lin J, Wilhelm FH, Wolkowitz OM, Cawthon R, Adler NE, et al. Cell aging in relation to stress arousal and cardiovascular disease risk factors. Psychoneuroendocrino. 2006; 31: 277287.

86. Solberg EE, Halvorsen R, Sundgot-Borgen J, Ingjer F, Holen A. Meditation: a modulator of the immune response to physical stress? A brief report. Brit J Sport Med. 1995; 29: 255-257.

87. Steensberg A, Toft AD, Bruunsgaard H, Sandmand M, Halkjaer-Kristensen J, Pedersen BK. Strenuous exercise decreases the percentage of type $1 \mathrm{~T}$ cells in the circulation. J Appl Physiol. 2001; 91: 1708-1712.

88. Davidson RJ, Kabat-Zinn J, Schumacher J, Rosenkanz M, Muller D, Santorelli SF, et al. Alterations in brain and immune function produced by mindfulness meditation. Psychosom Med. 2003; 65: 564-570.

89. Davidson RJ. Emotion and affective style: Hemispheric substrates. Psychol Sci. 1992; 3: 39-43.

90. Kang $\mathrm{DH}$, Davidson RJ, Coe CL, Wheeler RW, Tomarken AJ, Ershler WB. Frontal brain asymmetry and immune function. Behav Neurosci. 1991; 105: 860-869.

91. Taylor DM. Effects of a behavioral stress-management program on anxiety, mood, selfesteem, and T-cell count in HIV-positive men. Psychol Rep. 1995; 76: 451-457.

92. Robinson FP, Mathews HL, Witek-Janusek L. Psycho-endocrine-immune response to mindfulness-based stress reduction in individuals infected with the human immunodeficiency virus: a quasiexperimental study. J altern complem med. 2003; 9: 683-694.

93. Nyklicek I, Kuijpers KF. Effects of mindfulness-based stress reduction intervention on psychological well-being and quality of life: Is increased mindfulness indeed the mechanism?. Ann Behav Med. 2008, 35: 331-340.

94. Gayner B, Esplen MJ, Deroche P, Wong J, Bishop S, Kavanagh L, et al. A randomized controlled trial of mindfulness-based stress reduction to manage affective symptoms and improve quality of life in gay men living with HIV. J Behav Med. 2012; 35: 272-285.

95. Horberg MA, Silverberg MJ, Hurley LB, Towner WJ, Klein DB, Bersoff-Matcha S, et al. Effects of depression and selective serotonin reuptake inhibitor use on adherence to highly active antiretroviral therapy and on clinical outcomes in HIV-infected patients. J Acq Imm Def. 2008; 47: 384-390.

96. Kong MC, Nahata MC, Lacombe VA, Seiber EE, Balkrishnan R. Association between race, depression, and antiretroviral therapy adherence in a low-income population with HIV 
infection. J Gen Intern Med. 2012; 27: 1159-1164.

97. Nair MP, Saravolatz LD, Schwartz SA. Selective inhibitory effects of stress hormones on natural killer (NK) cell activity of lymphocytes from AIDS patients. Immunol Invest. 1995; 24: 689-699.

98. Turner BJ, Hecht FM, Ismail RB. CD4+ T-lymphocyte measures in the treatment of individuals infected with human immunodeficiency virus type 1 . A review for clinical practitioners. Arch Intern Med. 1994; 154: 1561-1573.

99. Février M, Dorgham K, Rebollo A. $\mathrm{CD}^{+} \mathrm{T}$ cell depletion in human immunodeficiency virus (HIV) infection: Role of apoptosis. Viruses. 2011; 3: 586-612.

100. Creswell JD, Myers HF, Cole SW, Irwin MR. Mindfulness meditation training effects on CD4+ T lymphocytes in HIV-1 infected adults: a small randomized controlled trial. Brain Behav Immun. 2009; 23: 184-188.

101. Gonzalez-Garcia M, Ferrer MJ, Borras X, Muñoz-Moreno JA, Miranda C, Puig J, et al. Effectiveness of Mindfulness-Based Cognitive Therapy on the Quality of Life, Emotional Status, and CD4 Cell Count of Patients Aging with HIV Infection. AIDS Behav. 2014; 18: 676-685.

102. Seyed Alinaghi S, Jam S, Foroughi M, et al. Randomized controlled trial of mindfulness-based stress reduction delivered to human immunodeficiency virus-positive patients in Iran: Effects on CD4(+) T lymphocyte count and medical and psychological symptoms. Psychosom Med. 2012; 74: 620-627.

103. Smith GR, McKenzie JM, Marmer DJ, Steele RW. Psychologic modulation of the human immune response to Varicella Zoster. Arch Intern Med. 1985; 145: 2110-2112.

104. Collins MP, Dunn LF. The effects of meditation and visual imagery on an immune system disorder: Dermatomyositis. J Altern Complement Med. 2005; 11: 275-284.

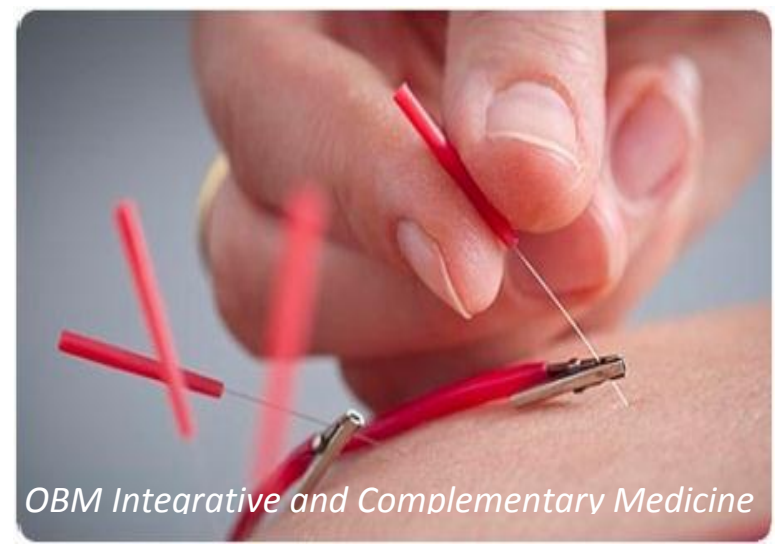

Enjoy OBM Integrative and Complementary Medicine by:

1. Submitting a manuscript

2. Joining in volunteer reviewer bank

3. Joining Editorial Board

4. Guest editing a special issue

For more details, please visit: http://www.lidsen.com/iournals/icm 